\title{
Vital capacity and selected metabolic diseases in middle-aged Japanese men
}

\author{
Hidenari Sakuta MD PhD ${ }^{1}$, Takashi Suzuki PhD ${ }^{2}$, Hiroko Yasuda MD PhD ${ }^{1}$, Teizo Ito MD PhD ${ }^{1}$
}

\begin{abstract}
H Sakuta, T Suzuki, H Yasuda, T Ito. Vital capacity and selected metabolic diseases in middle-aged Japanese men. Can Respir J 2006;13(2):79-82.

OBJECTIVE: To elucidate the association between vital capacity and the presence of selected metabolic diseases in middle-aged Japanese men.

METHODS: A cross-sectional analysis of the associations among forced vital capacity (FVC), static vital capacity as a percentage of that predicted (\%VC) and the presence of metabolic diseases was performed. RESULTS: In a univariate linear regression analysis, FVC and \%VC were inversely associated with poor vegetable intake, cigarette smoking and body mass index, but not with physical activity or ethanol consumption. In a logistic regression analysis adjusted for lifestyle factors, body mass index and age, the odds ratios for the presence of metabolic disease per $0.54 \mathrm{~L}$ (1 SD) decrease in FVC were 1.24 (95\% CI 1.03 to 1.50 ) for type II diabetes, 1.21 (95\% CI 1.02 to 1.42 ) for hypertension, 1.34 (95\% CI 1.11 to 1.63 ) for hypertriglyceridemia, 1.23 (95\% CI 1.03 to 1.46) for high gamma-glutamyl transferase levels and 1.63 (95\% CI 1.10 to 2.41) for an episode of cardiovascular disease. FVC did not correlate with hyperhomocysteinemia, hypercholesterolemia or high white blood cell count. Similar results were also obtained for the association between \% VC and metabolic diseases. CONCLUSIONS: A decrease in FVC or \% $\mathrm{VC}$ was associated with the presence of some metabolic diseases. The association may partly explain the reported association between low FVC and cardiovascular disease.
\end{abstract}

Key Words: Diabetes; Gamma-glutamyl transferase; Triglyceride; Vital capacity

\section{Capacité vitale et maladie métabolique chez des Japonais d'âge moyen}

OBJECTIF : Clarifier le lien entre la capacité vitale et la présence de
certaines maladies métaboliques chez des Japonais d'âge moyen.
MÉTHODES : Une analyse transversale des liens entre la capacité vitale
forcée (CVF), la capacité vitale statique, sous forme de pourcentage de la
valeur prévue (\%CV), et la présence de certaines maladies métaboliques
a été effectuée. RÉSULTATS : Dans une analyse de régression linéaire univariée, la CVF et le \%CV ont été en lien inversement proportionnel avec une consommation faible de légumes, le tabagisme et l'indice de masse corporelle (IMC), mais non avec la sédentarité ou la consommation d'alcool. Dans une analyse de régression logistique ajustée pour tenir compte de facteurs liés au mode de vie, à l'IMC et à l'âge, le risque relatif à l'égard de certaines maladies métaboliques associé à chaque diminution de 0,54 L (1 É.-T.) de CVF a été respectivement de 1,24 (IC $95 \% 1,03$ à 1,50) pour le diabète de type II, de 1,21 (IC $95 \% 1,02$ à 1,42) pour l'hypertension, de 1,34 (IC $95 \% 1,11$ à 1,63) pour l'hypertriglycéridémie, de 1,23 (IC $95 \%$ 1,03 à 1,46) pour la hausse des taux de gamma-glutamyl-transférase et de 1,63 (IC $95 \% 1,10$ à 2,41) pour un épisode de maladie cardiovasculaire. La CVF n'était pas en corrélation avec l'hyperhomocystéinémie, l'hypercholestérolémie ou la hausse de la formule leucocytaire. Des résultats similaires ont été obtenus pour ce qui est du lien entre le \%CV et les maladies métaboliques.

CONCLUSIONS : Une baisse de la CVF ou du \%CV a été associée à la présence de certaines maladies métaboliques. Cette observation pourrait en partie expliquer le lien entre la baisse de la CVF et la maladie cardiovasculaire.
$\mathrm{D}_{\mathrm{i}}^{\mathrm{s}}$ ecreased forced vital capacity (FVC) is associated with increased mortality (1). Low levels of FVC or static vital capacity (VC) predict myocardial infarction independently of heavy smoking, productive cough, exertional dyspnea and cardiac enlargement (2,3). A longitudinal study (4) has shown that $\mathrm{VC}$ inversely correlates with leg and carotid atherosclerosis. These associations may be explained by the relationship between FVC or VC and metabolic diseases or factors, including diabetes (5-7), hypertension $(8,9)$, triglyceride levels $(6,10,11)$, gamma $(\gamma)$-glutamyl transferase levels $(12,13)$ and markers of inflammation such as white blood cell (WBC) count (14), at least in part. However, the association between metabolic disease and FVC or VC has not been well elucidated in an Asian population. It is not known whether total homocysteine, an independent risk factor for cardiovascular disease (15), correlates with FVC or VC. In the present study, we analyzed the associations among FVC, $\mathrm{VC}$ as a percentage of that predicted (\%VC) and the presence of selected metabolic disorders in middle-aged Japanese men who belong to the Japan Self-Defense Forces.

\section{METHODS}

Men ( $\mathrm{n}=954)$ who underwent retirement medical checkups were studied. Of 1000 men who had undergone a retirement medical checkup from July 1999 to December 2000, 974 men agreed to participate in the study. Twenty of these men were excluded because of missing data. Thus, a total of 954 men were examined. Only men were studied because the proportion of women was less than $1 \%$ in the setting.

Serum total cholesterol, triglycerides and $\gamma$-glutamyl transferase levels, as well as fasting plasma glucose levels, were measured. 


\section{TABLE 1}

Characteristics of the study population $(n=954)$

\begin{tabular}{lc}
\hline Age, years* & $52.9 \pm 1.0$ \\
Current smokers, \% & 46.0 \\
Body mass index, $\mathrm{kg} / \mathrm{m}^{2}$ & $23.6 \pm 2.4$ \\
Forced vital capacity, L & $4.13 \pm 0.54$ \\
Percentage of predicted static vital capacity, \% & $115 \pm 13$ \\
Prevalence of disorders, \% & \\
Type II diabetes & 14.7 \\
Hypertension & 21.3 \\
Hyperhomocysteinemia & 6.4 \\
Hypertriglyceridemia & 15.4 \\
High gamma-glutamyl transferase & 20.2 \\
Hypercholesterolemia & 41.4 \\
High white blood cell count & 19.6 \\
Episode of cardiovascular disease & 3.2 \\
\hline
\end{tabular}

Data are expressed as means $\pm S D$, unless otherwise indicated. *Range 51 to 59 years of age (935 of 954 participants were 52 to 55 years of age)

An oral $75 \mathrm{~g}$ glucose tolerance test was performed. For the measurement of total homocysteine, fasting blood samples were collected in an EDTA tube in the morning, and the plasma was separated within $1 \mathrm{~h}$ after sample collection and stored at $-80^{\circ} \mathrm{C}$. Plasma total homocysteine was measured by using a fluorescence polarization immunoassay kit (Abbott IMx Homocysteine, Abbott Laboratories, USA) (16). Body mass index was calculated. VC and FVC were measured with an electronic spirometer (FUDAC-70, Fukuda Denshi Co Ltd, Japan). Predicted values of VC were obtained from linear regression analysis of age and height (17):

$$
\begin{aligned}
\text { Predicted VC for men } & =(27.63-0.112 \times \text { age [years] }) \times \\
\text { height }(\mathrm{cm}) &
\end{aligned}
$$

Information about cigarette smoking status and daily number of cigarettes smoked, as well as physical activity, ethanol consumption, vegetable intake and medical history, including episodes of cardiovascular disease, was obtained from a selfadministered questionnaire. The participant's habit of cigarette smoking was categorized as current smoking, ex-smoking or lifelong nonsmoking. Current physical activity was presented as the average weekly frequency of exercise causing sweating. Current ethanol consumption (millilitres of ethanol per day) was calculated from the consumption volume of each type of alcoholic beverage. Current vegetable intake was classified into four categories: very rich intake, rich intake, common intake and poor intake. Each category was given a score of $4,3,2$ or 1 , respectively, which was designated as the vegetable intake score. Plasma folate, which is found in rich concentrations in vegetables and is regarded as a biomarker of vegetable intake (18), was measured with a chemiluminescent kit (Bayer HealthCare LLC, USA). The vegetable intake score was inversely associated with plasma levels of folate (found in vegetables) in the population studied (standard regression coefficient $=0.082 ; \mathrm{P}=0.011$.

Hypercholesterolemia was defined as a serum total cholesterol concentration of more than $5.69 \mathrm{mmol} / \mathrm{L}$ or receiving medication for hypercholesterolemia. Hypertriglyceridemia was defined as a serum triglyceride concentration of more than $2.24 \mathrm{mmol} / \mathrm{L}$ or receiving medication for hypertriglyceridemia. A peripheral WBC count of $6.9 \times 10^{9} / \mathrm{L}$ or more (upper 20th percentile of the studied population) was defined as a high WBC count. Type II diabetes

\begin{tabular}{|c|c|c|c|c|}
\hline & \multicolumn{2}{|c|}{ FVC } & \multicolumn{2}{|c|}{$\% \mathrm{VC}$} \\
\hline & $\beta$ & $\mathbf{P}$ & $\beta$ & $\mathbf{P}$ \\
\hline Age & 0.038 & 0.244 & 0.097 & 0.003 \\
\hline \multicolumn{5}{|l|}{ Lifestyle factors } \\
\hline Frequency of sweating exercise per week & 0.037 & 0.256 & 0.047 & 0.144 \\
\hline Ethanol consumption per day & 0.042 & 0.200 & 0.040 & 0.219 \\
\hline Vegetable intake score & 0.064 & 0.049 & 0.075 & 0.020 \\
\hline Number of cigarettes smoked per day & -0.105 & 0.001 & -0.114 & $<0.001$ \\
\hline Body mass index & -0.100 & 0.002 & -0.074 & 0.022 \\
\hline \multicolumn{5}{|l|}{ Metabolic parameters* } \\
\hline Fasting plasma glucose & -0.051 & 0.123 & -0.067 & 0.039 \\
\hline Systolic blood pressure & -0.079 & 0.022 & -0.089 & 0.009 \\
\hline Total homocysteine & 0.031 & 0.335 & 0.021 & 0.517 \\
\hline Triglyceride & -0.114 & 0.001 & -0.096 & 0.006 \\
\hline Gamma-glutamyl transferase & -0.021 & 0.517 & -0.038 & 0.253 \\
\hline Total cholesterol & -0.010 & 0.769 & -0.002 & 0.943 \\
\hline White blood cell count & -0.139 & $<0.001$ & -0.144 & $<0.001$ \\
\hline
\end{tabular}

TABLE 2

*Analysis of metabolic parameters was adjusted for age, physical activity, daily ethanol consumption, vegetable consumption, daily number of cigarettes smoked and body mass index. $\beta$ Standard regression coefficient

was diagnosed based on the criteria of the World Health Organization (19). Persons who showed a 'diabetic pattern' in the tolerance test had diabetes diagnosed. The status of diabetes was determined by the self-reporting of physician-diagnosed diabetes or by an oral $75 \mathrm{~g}$ glucose tolerance test. No participants were subject to insulin therapy at the time of admission. Cut-off levels of plasma total homocysteine and serum $\gamma$-glutamyl transferase were $14 \mu \mathrm{mol} / \mathrm{L}$ (15) and $70 \mathrm{U} / \mathrm{L}$, respectively. Hypertension was diagnosed based on individual medical history or having received medication for hypertension (blood pressure of at least $140 / 90 \mathrm{mmHg}$ ) based on the criteria of the Seventh Report of the Joint National Committee on Prevention, Detection, Evaluation, and Treatment of High Blood Pressure (20). Blood pressure was measured with a mercury sphygmomanometer after the participant had been at rest in a sitting position. The participants gave informed consent. The study protocol was approved by the Ethics Committee of the Self-Defense Forces Central Hospital, Tokyo, Japan.

A linear regression analysis was performed with $\mathrm{FVC}$ or $\% \mathrm{VC}$ as the dependent variable, and with lifestyle factors and metabolic parameters as the independent variables. A logistic regression analysis was also performed to obtain odds ratio per $0.54 \mathrm{~L}(1 \mathrm{SD})$ decrease in FVC or per 13\% (1 SD) decrease in $\% \mathrm{VC}$ for the presence of the selected metabolic disorders. Statistical analysis was performed using StatView version 5.0 (SAS Institute, USA).

\section{RESULTS}

Characteristics of the study population are shown in Table 1. Of lifestyle factors studied, vegetable intake was positively associated with FVC and \%VC (Table 2). The daily number of cigarettes smoked and body mass index were inversely associated with FVC and \%VC. Neither frequency of sweating exercise nor daily ethanol consumption was associated with FVC or \%VC. 
TABLE 3

Odds ratios for the presence of metabolic disease per $0.54 \mathrm{~L}$ (1 SD) decrease in forced vital capacity (FVC) and per $13 \%$ (1 SD) decrease in percentage of predicted vital capacity $(\% \mathrm{VC})$ for the presence of metabolic disease among all participants irrespective of smoking status $(n=954)$

\begin{tabular}{|c|c|c|c|c|}
\hline Metabolic disease & $\begin{array}{c}\text { OR }(95 \% \mathrm{Cl}) \\
\text { per } 0.54 \mathrm{~L} \text { decrease in FVC }\end{array}$ & $\mathbf{P}$ & $\begin{array}{c}\text { OR }(95 \% \mathrm{Cl}) \\
\text { per } 13 \% \text { decrease in } \% \mathrm{VC}\end{array}$ & $\mathbf{P}$ \\
\hline Type II diabetes & $1.24(1.03-1.50)$ & 0.025 & $1.27(1.06-1.53)$ & 0.010 \\
\hline Hypertension & $1.21(1.02-1.42)$ & 0.027 & $1.20(1.03-1.41)$ & 0.023 \\
\hline Hyperhomocysteinemia & $0.88(0.68-1.14)$ & 0.329 & $0.89(0.69-1.15)$ & 0.364 \\
\hline Hypertriglyceridemia & $1.34(1.11-1.63)$ & 0.003 & $1.29(1.08-1.56)$ & 0.006 \\
\hline High gamma-glutamyl transferase levels & $1.23(1.03-1.46)$ & 0.021 & $1.22(1.03-1.44)$ & 0.021 \\
\hline Hypercholesterolemia & $1.06(0.93-1.21)$ & 0.411 & $1.02(0.90-1.16)$ & 0.731 \\
\hline High white blood cell count & $1.13(0.94-1.35)$ & 0.201 & $1.16(0.97-1.38)$ & 0.110 \\
\hline Episode of cardiovascular disease & $1.63(1.10-2.41)$ & 0.016 & $1.52(1.05-2.20)$ & 0.027 \\
\hline
\end{tabular}

Analysis was adjusted for age, physical activity, daily ethanol consumption, vegetable consumption, daily number of cigarettes smoked and body mass index

TABLE 4

Odds ratios for the presence of metabolic disease per $0.54 \mathrm{~L}$ (1 SD) decrease in forced vital capacity (FVC) and per $13 \%$ (1 SD) decrease in percentage of predicted vital capacity (\%VC) for the presence of metabolic disease among lifelong nonsmokers $(n=201)$

\begin{tabular}{|c|c|c|c|c|}
\hline Metabolic disease & $\begin{array}{c}\mathrm{OR}(95 \% \mathrm{Cl}) \\
\text { per } 0.54 \mathrm{~L} \text { decrease in } \mathrm{FVC}\end{array}$ & $\mathbf{P}$ & $\begin{array}{c}\text { OR }(95 \% \mathrm{Cl}) \\
\text { per } 13 \% \text { decrease in \%VC }\end{array}$ & $\mathbf{P}$ \\
\hline Hypertension & $1.39(0.91-2.10)$ & 0.125 & $1.33(0.89-1.98)$ & 0.165 \\
\hline Hypertriglyceridemia & $1.82(1.11-2.98)$ & 0.018 & $1.73(1.08-2.78)$ & 0.023 \\
\hline High gamma-glutamyl transferase levels & $1.27(0.84-1.91)$ & 0.252 & $1.19(0.80-1.77)$ & 0.380 \\
\hline Episode of cardiovascular disease & $0.78(0.29-2.13)$ & 0.626 & $0.70(0.27-1.82)$ & 0.468 \\
\hline
\end{tabular}

Analysis was adjusted for age, physical activity, daily ethanol consumption, vegetable consumption and body mass index

With regard to metabolic parameters, systolic blood pressure, triglyceride levels and WBC count, but not total homocysteine, $\gamma$-glutamyl transferase or total cholesterol levels, correlated with FVC and \% VC in a linear regression analysis model adjusted for physical activity, daily ethanol consumption, vegetable consumption, cigarette smoking, body mass index and age. Fasting plasma glucose levels correlated with \%VC but not with FVC.

In a logistic regression analysis model adjusted for the abovementioned lifestyle factors, as well as body mass index and age, a decrease of $1 \mathrm{SD}$ of FVC $(0.54 \mathrm{~L})$ or a decrease of $1 \mathrm{SD}$ of \%VC (13\%) was associated with the presence of type II diabetes, hypertension, hypertriglyceridemia, high $\gamma$-glutamyl transferase levels and having had an episode of cardiovascular disease, but not with the presence of hyperhomocysteinemia, hypercholesterolemia or a high WBC count (Table 3).

A stratified analysis was performed among lifelong nonsmokers $(n=201)$ to lessen the possible effect of cigarette smoking (Table 4). From the stratification, the odds ratio per $0.54 \mathrm{~L}$ decrease in $\mathrm{FVC}$ or per 13\% decrease in \%VC for type II diabetes, hypertension and hypertriglyceridemia, but not for high $\gamma$-glutamyl transferase levels, increased. The association became not significant for hypertension or high $\gamma$-glutamyl transferase levels after the stratification.

\section{DISCUSSION}

It has been shown that FVC and VC predict future development of arterial atherosclerosis (21), diabetes and insulin resistance (5-7,22-24), and hypertension (8,9). In baseline cross-sectional studies $(6,10)$, triglyceride concentrations have been shown to inversely correlate with FVC or VC. Consistent with these previous reports, the present study showed that both FVC and \%VC were inversely associated with the presence of type II diabetes, hypertriglyceridemia and hypertension (Table 3).

The mechanism of the association is not clear, although lifestyle factors may contribute to it. Cigarette smoking (10), physical inactivity (25), poor vegetable intake (26), ethanol consumption (11) and obesity are known to inversely correlate with FVC and \%VC. In the present study, however, the association between metabolic diseases and VC was independent of these lifestyle factors and body mass index (Table 3).

Another possible mechanism of the association is insulin resistance $(6,10)$. Waist to hip circumference ratio, which is known to correlate with insulin resistance, has been shown to correlate with FVC independently of body mass index $(27,28)$. Obesity, diabetes and hypertension, which are also known to correlate with insulin resistance, inversely correlated with FVC and \% VC in the present study, as reported by others $(5-9,29)$. It has also been shown that a decrease in FVC or $\% \mathrm{VC}$ correlates with insulin resistance $(6,23,24)$. However, insulin resistance may not be the cause of decreased VC because it has been shown that a decrease in $\mathrm{VC}$ precedes insulin resistance (23). In this context, it is speculated that early-life factors can affect lung growth and also program insulin resistance $(6,24)$. 
Serum $\gamma$-glutamyl transferase activity, a marker of oxidative stress $(13,30)$ and also a risk factor for cardiovascular disease (12), predicts cardiovascular disease (12) and diabetes (31). In the present study, high $\gamma$-glutamyl transferase levels were inversely associated with FVC and \%VC. Although the association between FVC and $\gamma$-glutamyl transferase levels has previously been reported, the activity of the enzyme is regarded as a marker of ethanol consumption in that report (11). Thus, as far as we know, the present report is the first to show that $\gamma$-glutamyl transferase levels correlate with FVC or \%VC independently of ethanol consumption. Because total homocysteine did not correlate with FVC or \%VC, total homocysteine does not seem to mediate the association between lung function and cardiovascular disease.

\section{CONCLUSIONS}

Decreased FVC and \%VC was associated with the presence of type II diabetes, hypertension, hypertriglyceridemia and high $\gamma$-glutamyl transferase levels in middle-aged Japanese men.

\section{REFERENCES}

1. Neas LM, Schwartz J. Pulmonary function levels as predictors of mortality in a national sample of US adults. Am J Epidemiol 1998;147:1011-8.

2. Keys A, Aravanis C, Blackburn H, et al. Lung function as a risk factor for coronary heart disease. Am J Public Health 1972;62:1506-11.

3. Friedman GD, Klatsky AL, Siegelaub AB. Lung function and risk of myocardial infarction and sudden cardiac death. N Engl J Med 1976;294:1071-5.

4. Engstrom G, Hedblad B, Valind S, Janzon L. Asymptomatic leg and carotid atherosclerosis in smokers is related to degree of ventilatory capacity: Longitudinal and cross-sectional results from 'Men born in 1914', Sweden. Atherosclerosis 2001;155:237-43.

5. Engstrom G, Janzon L. Risk of developing diabetes is inversely related to lung function: A population-based cohort study. Diabet Med 2002;19:167-70.

6. Lawlor DA, Ebrahim S, Smith GD. Associations of measures of lung function with insulin resistance and type 2 diabetes: Findings from the British Women's Heart and Health Study. Diabetologia 2004;47:195-203.

7. Engstrom G, Hedblad B, Nilsson P, Wollmer P, Berglund G, Janzon L. Lung function, insulin resistance and incidence of cardiovascular disease: A longitudinal cohort study. J Intern Med 2003;253:574-81.

8. Engstrom G, Wollmer P, Valind S, Hedblad B, Janzon L. Blood pressure increase between 55 and 68 years of age is inversely related to lung function: Longitudinal result from the cohort study 'Men born in 1914'. J Hypertens 2001;19:1203-8.

9. Wu Y, Vollmer WM, Buist AS, et al; PRC-USA Cardiovascular and Cardiopulmonary Epidemiology Research Group. Relationship between lung function and blood pressure in Chinese men and women of Beijing and Guangzhou. Int J Epidemiol 1998;27:49-56.

10. Yeh HC, Punjabi NM, Wang NY, Pankow JS, Duncan BB, Brancati FL. Vital capacity as a predictor of incident type 2 diabetes: The Atherosclerosis Risk in Communities study. Diabetes Care 2005;28:1472-9.

11. Zureik M, Liard R, Kauffmann F, Henry C, Neukirch F. Alcohol consumption, gamma-glutamyl transpeptidase (GGT), and pulmonary function: A cross-sectional and longitudinal study in working men. Alcohol Clin Exp Res 1996;20:1507-11.
12. Wannamethee G, Ebrahim S, Shaper AG. Gamma-glutamyltransferase: Determinants and association with mortality from ischemic heart disease and all causes. Am J Epidemiol 1995;142:699-708.

13. Whitfield JB. Gamma glutamyl transferase. Crit Rev Clin Lab Sci 2001;38:263-355.

14. Kannel WB, Anderson K, Wilson PW. White blood cell count and cardiovascular disease. Insights from the Framingham Study. JAMA 1992;267:1253-6

15. Hackam DG, Peterson JC, Spence JD. What level of plasma homocyst(e)ine should be treated? Effects of vitamin therapy on progression of carotid atherosclerosis in patients with homocyst(e)ine levels above and below $14 \mathrm{micromol} / \mathrm{L}$. Am J Hypertens 2000;13:105-10.

16. Shipchandler MT, Moore EG. Rapid, fully automated measurement of plasma homocyst(e)ine with the Abbott IMx analyzer. Clin Chem 1995;41:991-4.

17. Baldwin ED, Cournand A, Richards DW Jr. Pulmonary insufficiency. I. Physiological classification, clinical methods of analysis, standard values in normal subjects. Medicine 1948;27:243-78.

18. Brevik A, Vollset SE, Tell GS, et al. Plasma concentration of folate as a biomarker for the intake of fruit and vegetables: The Hordaland Homocysteine Study. Am J Clin Nutr 2005;81:434-9.

19. World Health Organization Consultation. Definition, Diagnosis and Classification of Diabetes Mellitus and its Complications. Part 1: Diagnosis and Classification of Diabetes Mellitus. Geneva: WHO, 1999.

20. Chobanian AV, Bakris GL, Black HR, et al; National Heart, Lung, and Blood Institute Joint National Committee on Prevention, Detection, Evaluation, and Treatment of High Blood Pressure; National High Blood Pressure Education Program Coordinating Committee. The Seventh Report of the Joint National Committee on Prevention, Detection, Evaluation, and Treatment of High Blood Pressure: The JNC 7 report. JAMA 2003;289:2560-72. (Erratum in 2003;290:197).

21. Engstrom G, Lind P, Hedblad B, et al. Lung function and cardiovascular risk: Relationship with inflammation-sensitive plasma proteins. Circulation 2002;106:2555-60.

22. Lange P, Parner J, Schonohr P, Jensen G. Copenhagen City Heart Study: Longitudinal analysis of ventilatory capacity in diabetic and nondiabetic adults. Eur Respir J 2002;20:1406-12.

23. Lazarus R, Sparrow D, Weiss ST. Impaired ventilatory function and elevated insulin levels in nondiabetic males: The Normative Aging Study. Eur Respir J 1998;12:635-40.

24. Lazarus R, Sparrow D, Weiss ST. Baseline ventilatory function predicts the development of higher levels of fasting insulin and fasting insulin resistance index: The Normative Aging Study. Eur Respir J 1998;12:641-5.

25. Cooper KH, Pollock ML, Martin RP, White SR, Linnerud AC, Jackson A. Physical fitness levels vs selected coronary risk factors. A cross-sectional study. JAMA 1976;236:166-9.

26. Samet JM, Hatch GE, Horstman D, et al. Effect of antioxidant supplementation on ozone-induced lung injury in human subjects. Am J Respir Crit Care Med 2001;164:819-25.

27. Lazarus R, Gore CJ, Booth M, Owen N. Effects of body composition and fat distribution on ventilatory function in adults. Am J Clin Nutr 1998;68:35-41.

28. Lazarus R, Sparrow D, Weiss ST. Effects of obesity and fat distribution on ventilatory function: The normative aging study. Chest 1997;111:891-8.

29. Bray GA. Complications of obesity. Ann Intern Med 1985;103:1052-62.

30. Lee DH, Blomhoff R, Jacobs DR Jr. Is serum gamma glutamyltransferase a marker of oxidative stress? Free Radic Res 2004;38:535-9.

31. Perry IJ, Wannamethee SG, Shaper AG. Prospective study of serum gamma-glutamyltransferase and risk of NIDDM. Diabetes Care 1998;21:732-7. 


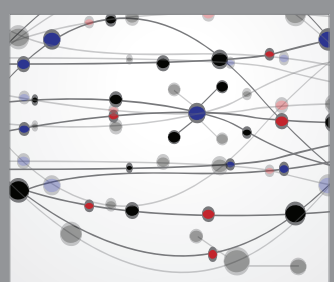

The Scientific World Journal
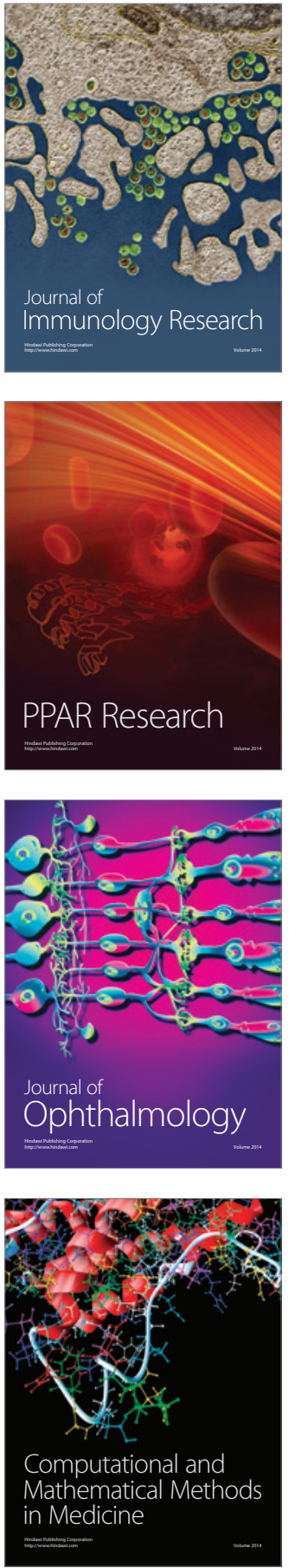

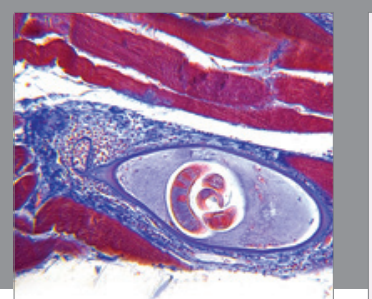

Gastroenterology Research and Practice

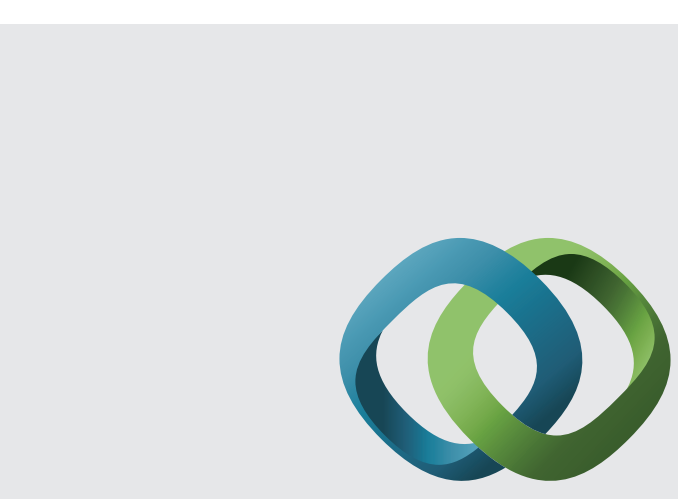

\section{Hindawi}

Submit your manuscripts at

http://www.hindawi.com
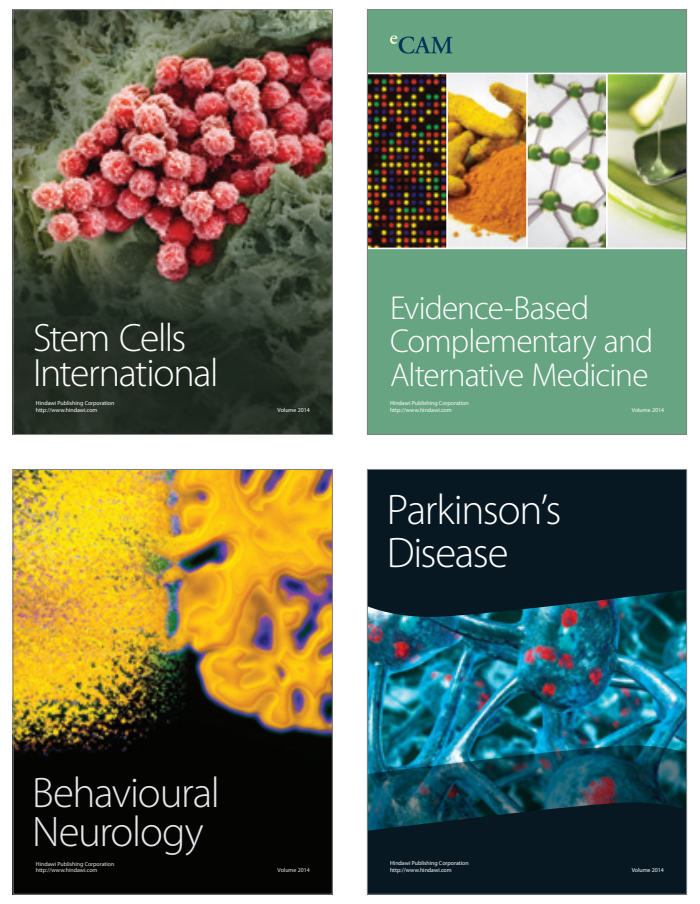
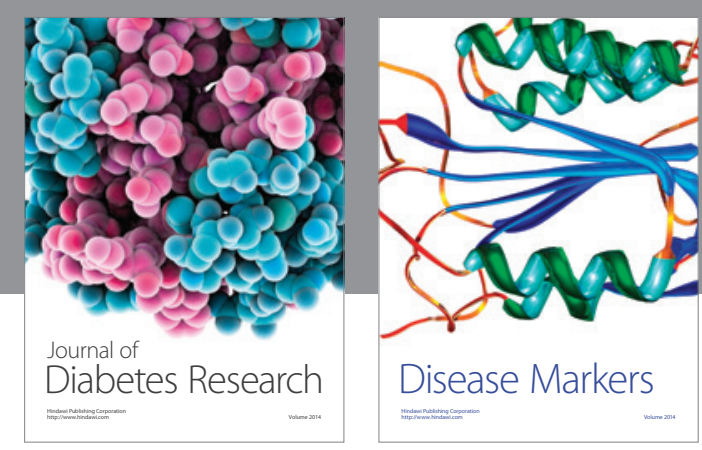

Disease Markers
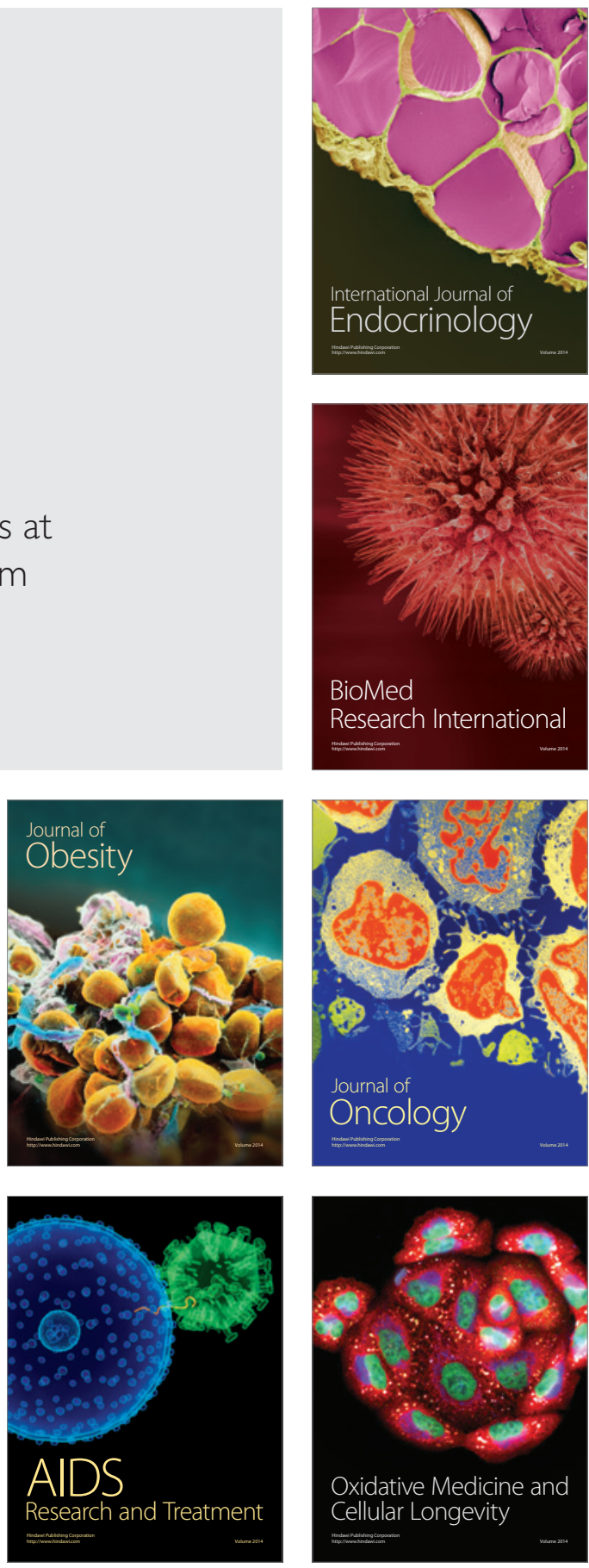